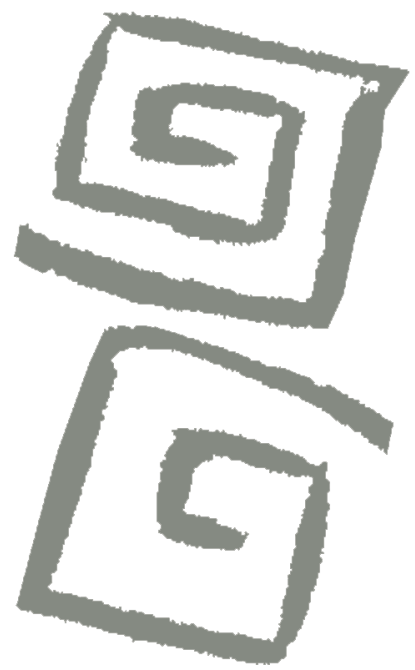

\title{
El racionalismo y la descorporalización moderna del parto: por una ecología del nacimiento
}

\author{
Rationalism and the disembodiment of modern \\ childbirth: the case for an ecology of childbirth
}

Federico Ignacio Viola ${ }^{1}$, Ana María Bonet de Viola², Marisa Espinoza ${ }^{3}$

${ }^{1}$ Doctor en Filosofía. Investigador Asistente, Instituto de Filosofía, Universidad Católica de Santa Fe; Consejo Nacional de Investigaciones Científicas y Técnicas, Santa Fe, Argentina. $\square$ (iD)

${ }^{2}$ Doctora en Derecho. Docente Investigadora Universidad Católica de Santa Fe, Consejo Nacional de Investigaciones Científicas y Técnicas, Santa Fe, Argentina. $\triangle$ (iD

${ }^{3}$ Médica Tocoginecóloga. Docente Investigadora Universidad Católica de Santa Fe, Universidad Nacional del Litoral. Santa Fe, Argentina. $\triangle$ iD
RESUMEN El presente artículo ofrece una genealogía del paradigma biomédico del parto, con el objetivo de deconstruir los principios del racionalismo que condujeron a la objetivación del cuerpo y la consecuente mercantilización del nacimiento. Se pretende demostrar cómo dicha concepción del cuerpo y de la sensibilidad determina el proceso del nacimiento, en tanto acontecimiento de carácter relacional. Metodológicamente, esta deconstrucción se lleva a cabo a través de una genealogía crítico-descriptiva de los presupuestos teóricos de la concepción racionalista del cuerpo. A través del desarrollo del concepto de ecología del parto se propone, a su vez, repensar dicho carácter relacional a partir de una propuesta valorativa de lo corporal, es decir del cuerpo entendido como lenguaje de proximidad tomando como marco de referencia teórico la ética de la diferencia. Esta reivindicación del carácter ecológico-relacional de la sensibilidad tiene potencial para instaurar una dinámica de cooperación y responsabilidad que subvierta la lógica racionalista del control y el dominio que rige el paradigma biomédico vigente.

PALABRAS CLAVES Nacimiento; Mercantilización; Control Social; Medicalización; Obstetricia.

\begin{abstract}
The paper proposes a genealogy of the biomedical paradigm surrounding childbirth, with the aim of deconstructing the principles of rationalism that led to the objectification of the body and to the consequent commodification of birth. We intend to demonstrate how such a conception of the body and of sensibility determines the birth process, which leads us to consider it an event that is relational in nature. Methodologically, this deconstruction is carried out through a critical-descriptive genealogy of the theoretical assumptions of the rationalist conception of the body. By developing the concept of ecology of childbirth, we intend to call into question this relational nature of the body and to recover the value of corporeality and embodiment as a language of proximity, within a theoretical framework of the ethics of difference. This vindication of the ecologicalrelational nature of sensibility has the potential to establish a dynamic of responsibility and cooperation capable of subverting the rationalist logic of control and the dominion of the current biomedical paradigm.
\end{abstract}

KEY WORDS Birth; Commodification; Social Control; Medicalization; Obstetrics. 


\section{INTRODUCCIÓN}

La incorporación de los postulados iluministas y racionalistas modernos al ámbito de la medicina generó un complejo proceso de cientifización y medicalización del tratamiento de la salud que, en el ámbito de la obstetricia, se plasmó en la industrialización e intervencionismo sobre el nacimiento.

El racionalismo moderno generó una ilusión de dominio de la razón sobre el mundo natural que luego se transfirió al proceso del parto. El resultado que siguió fue una concepción puramente medicalizada del parto que respondiera a las pretensiones médicas e institucionales de control total de la situación, así como de la mujer y del recién nacido.

Este trabajo parte de la premisa de que el proceso de industrialización del nacimiento es un subproducto del enfoque moderno racionalista, centrado en la ciencia y en la técnica, que generó una progresiva descorporalización y descontextualización del nacimiento. Para poner de manifiesto este vínculo entre descorporalización y racionalismo moderno se lleva a cabo una deconstrucción teórico reflexiva de la concepción racionalista del cuerpo y se intenta mostrar a la praxis obstétrica actual como uno de sus resultados.

Esta deconstrucción se lleva a adelante mediante una genealogía(1), en cuanto método de análisis discursivo, que permite una selección, acaso un tanto arbitraria, de ciertos factores considerados más relevantes respecto de la conformación del fenómeno estudiado.

Al poner de relieve la conformación dispersa, discontinua y regular de los discursos ${ }^{(1)}$, esta metodología permite enfatizar, precisamente, que el fenómeno actual ${ }^{(2)}$ es el resultado en cierta manera arbitrario de contingencias pasadas $^{(3)}$. Son aquellas contingencias significantes para la conformación del fenómeno en cuestión, en este caso el nacimiento, precisamente las que permiten abordar el método genealógico aquí empleado, incluso renunciando al abordaje de otros factores también influyentes.

Por lo tanto, a diferencia de una cronología, no se pretende una exposición exhaustiva del fenómeno como hecho histórico, sino más bien su abordaje como un complejo entramado de múltiples factores. Se trata, en efecto, de abordar conscientemente algunos de aquellos factores teóricos que conforman el paradigma biomédico del nacimiento, como tirar de un hilo para desenmarañar un entramado complejo, procurando así deconstruir los postulados que tejieron su trama.

Finalmente, y a modo de discusión, se bosquejan perspectivas y lineamientos alternativos como propuestas inspiradoras para la construcción de un nuevo paradigma del nacimiento. En este sentido, se propone una aproximación a la corporalidad que revise el paradigma de control y dominio, en vistas de superar la concepción moderna del cuerpo como objeto, para inaugurar una corporalidad de la responsabilidad. Por tratarse de un análisis teórico-reflexivo se abre esta discusión final como perspectiva para futuros debates, evitando así postular conclusiones últimas que obturarían el proceso deconstructivo, un proceso que no se deja clausurar.

A partir de la propuesta discursiva en torno al concepto de ecología del parto, se procura asimismo realizar un aporte para la construcción de un nuevo paradigma del nacimiento. Esto conlleva la postulación de un ámbito que se sustrae a todo poder y control, ámbito en el que prima la responsabilidad como vínculo intersubjetivo primordial. La incursión en este ámbito de "no control", de irracionalidad, implica la reincorporación de aspectos decisivos, dejados de lado por la medicina moderna occidental, como los emocionales, espirituales, corporales, ambientales y, sobre todo, relacionales.

\section{LA DESCORPORALIZACIÓN MODERNA DEL PARTO}

La ciencia moderna, con el auspicio estatal, legitimó el paradigma biomédico o tecnocrático de la medicina ${ }^{(4,5)}$, como modelo hegemónico del cuidado de la salud. Este modelo se sustenta sobre un paradigma racionalista y cientificista de la medicina que concibe 
al hombre como sustraído de su propia corporalidad generando una dicotomía entre la mente y el cuerpo ${ }^{(6)}$.

En los siguientes apartados se procurará analizar genealógicamente la influencia del racionalismo en la conformación de este paradigma que domina las prácticas actuales en torno al nacimiento. Se parte del presupuesto de que la escisión teórica entre cuerpo y mente generada por el racionalismo iluminista justificó la objetivación del cuerpo y de esta manera la descorporalización de los procesos biológicos, entre ellos, el parto, habilitando su mecanización, su industrialización, en favor de su control y explotación comercial.

El método genealógico permite un abordaje del fenómeno de la descorporalización a partir de los discursos que mientan la corporalidad. A través de un enfoque perspectivista, se procura una aproximación teórica asentada en la fuerza discursiva de la práctica en la que se manifiestan los discursos. De esta manera, se abordan los discursos sobre la corporalidad en cuanto prácticas que desenmascaran las explicaciones en sus propias manifestaciones, antes que como condiciones posibilitantes -eventualmente empíricas- de racionalidad. Ello, por su parte, habilita una aproximación que se independiza de la evidencia empírica, en tanto requisito epistemológico de una ciencia de tradición metafísica, asentada en una verdad de significaciones ideales e indefinidos teleológicos ${ }^{(7)}$.

\section{El racionalismo y la objetivación del cuerpo}

Los antecedentes del paradigma biomédico se remontan al surgimiento de la modernidad, a la asimilación de los postulados racionalistas e iluministas por parte de las ciencias $y$, en general, de la cultura occidental. La separación mente-cuerpo es reflejo de una lógica clasificatoria típica de la razón moderna cuyo lema principal es la claridad y la distinción ${ }^{(8)}$. Esta lógica constituye el principal instrumento de control de la razón moderna que, para dominar debe ordenar, dividir, clasificar según sus parámetros y esquemas ${ }^{(9)}$.
La exacerbación de lo racional como aspecto principal de lo humano resultó en la jerarquización de la mente y del espíritu por sobre el cuerpo y la sensibilidad, lo cual condujo a la separación virtual entre materia e interioridad $^{(10,5)}$. Esta separación dio lugar a una aproximación racionalista de la interioridad humana, comprendida como cogito, como entendimiento, como mente, por lo que se asume gobernada por las leyes de la lógica(11). De esta forma, la interioridad, la "espiritualidad" humana, fue reducida al saber, al conocimiento en tanto capacidad de captación del mundo como objeto, como dato empírico cuantificable y manipulable. El mundo en tanto res extensa, se entrega, es "dato" que se ofrece al control de la mente-espíritu a la que nada se le sustrae.

El cuerpo, perteneciente al mundo, al entorno, a la naturaleza, queda sometido así a la lógica racionalista de la mente que lo domina. Ello generó, en primer lugar, la reducción de la vida a la bio-logía, a los datos cuantificables y mensurables con los que trabaja la ciencia. En segundo lugar, esta lógica racionalista de la cuantificación habilitó, por su parte, la transformación del cuerpo en una máquina $^{(12)}$ la cual, susceptible de ser dividida en partes, puede ser reparada desde afuera. Frente a estos procesos de objetivación, el espíritu y la mente parecían poder permanecer inmutables ${ }^{(5)}$.

La dignidad del sujeto moderno se circunscribe de esta forma a la autonomía, a la libertad y, sobre todo, a la soberanía que le otorga su condición de ser racional. El sujeto humano llega a ser considerado como esencialmente soberano de sí mismo, de su cuerpo, controlador de su sensibilidad, emociones y también del entorno.

\section{Cuerpo y parto}

Por desviarse del modelo masculino ideal de cuerpo-máquina, el cuerpo femenino fue considerado por la medicina, desde sus orígenes, como una excepción defectuosa e imperfecta. Por su parte, la dinámica cambiante e imprevisible que lo gobierna desembocó en 
su consideración como un objeto cuya manipulación implicaba altos niveles de riesgo que debían ser dominados por la ciencia. Por eso, la obstetricia moderna se ocupa no solo de un cuerpo-máquina, sino además de uno que es, ante todo, defectuoso, incontrolable y desviado de los estándares preestablecidos científicamente $\mathrm{e}^{(13,5)}$.

Esta infravaloración de la corporalidad femenina generó, por un lado, la subestimación de la capacidad de la gestante de llevar adelante el proceso del parto y, a su vez, acarreó la sobrevaloración del conocimiento científico, al tiempo que adjudicó a los profesionales de la salud una legitimación desproporcionada en su proceder técnico científico. Esto impactó en la consecuente institucionalización y medicalización sistemática de los nacimientos, generando además una asimetría en las relaciones entre los que asisten el nacimiento y las gestantes. A ellas se les asignó entonces un rol pasivo y de sumisión, habilitando prácticas de sometimiento e intervencionismo. Estas prácticas fueron instauradas en el imaginario común, naturalizándose como sinónimos de cuidado y buena atención, lo que generó que no solo sean aceptadas y toleradas, sino además que a menudo sean solicitadas como únicos medios de asistencia médica eficiente ${ }^{(14)}$.

La gestante es asimilada así a una "pa-

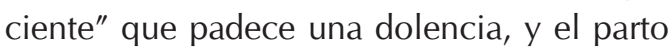
a una "enfermedad" que hay que curar. De esta forma la asimetría mente-cuerpo se corresponde a la asimetría profesional-gestante, según la cual el profesional ejerce en el rol de la ciencia que manipula, y la gestante padece en el rol del objeto expuesto a la manipulación y al control, que debe ser arreglado y curado(15,16).

En este esquema dual, los individuos se comprenden a sí mismos como diferentes de su cuerpo, como si su dignidad residiese "en otro lado" y por ello se prestan, "prestan sus cuerpos", para situaciones que los alienan, pero de las cuales ellos pretenden estar sustraídos. La libertad es entonces más propia que la corporalidad, y la dignidad que la reviste reside por tanto en la autonomía subjetiva, es decir, en la capacidad de disponer de todo lo que se posee, entre ello, el propio cuerpo. El acto de la decisión resguarda de esta forma la "dignidad", sin importar el ultraje que se reciba, pues es la misma libertad la que pone a salvo la dignidad, pues coincide con ella. De esta manera, el discurso que exalta y reivindica la libertad como valor supremo, legitima la alienación sistemática que se lleva a cabo tanto desde la práctica médica, en cuanto trabaja con "objetos inertes", como desde lo individual-personal en cuanto cada individuo se considera poseedor de un cuerpo-objeto del que se puede escindir y del que puede disponer.

Esta alienación, esta enajenación de sí mismo respecto de lo corporal se expresa tanto en la relación de la gestante con su propio cuerpo, como en el trato anónimo que recibe de parte del profesional. Ejemplo de ello es la situación en la que la gestante decide una cesárea no solo para no sentir dolor sino "para no sentir nada", enajenándose de su cuerpo, entregándolo para la intervención. La misma enajenación puede detectarse cuando no se le llama por su nombre, pasando a denominar el todo por la parte. La gestante (todo) pasa a ser el objeto tratado ("una cesárea"). Esta alienación sistemática, disimulada por el discurso aséptico de la ciencia que promete la seguridad total, no logra dar significado a lo corporal si no es partiendo de una posición de dominación, de sometimiento y de control.

Esta lógica dual y asimétrica no logra ser superada ni siquiera a partir de los primeros intentos feministas de reivindicación igualitaria que, en la búsqueda de reconocimiento, han dejado de lado las experiencias femeninas corpóreas del nacimiento y la sexualidad, priorizando los aspectos iluministas, racionalistas y eficientistas modernos relacionados con la actividad intelectual, política y, sobre todo, económica. En este sentido, Goberna Tricas $^{(17)}$ refiere a los trabajos de Betty Friedman (La mística de la maternidad) y de Simone de Beauvoir (El segundo sexo) que, más allá de sus aportes para la emancipación de la mujer, y ciertamente en rechazo a una cierta reducción del rol de la mujer a la maternidad como destino natural, en nombre de la igualdad han propendido un realce intelectualista como reivindicación de libertad femenina, reafirmando 
así el menosprecio moderno de la experiencia corpórea. Paradójicamente, ello contribuyó a la consolidación de la objetivación del cuerpo femenino ${ }^{(17)}$. En este sentido deben reconocerse aportes más recientes dentro del feminismo, que refieren a un rol fundamental de la corporalidad en el proceso emancipatorio, e incluso del potencial relacional del cuerpo, en tanto ámbito de relación al mundo ${ }^{(8)}$.

\section{Parto, tecnocracia y hegemonía}

La jerarquización y sobreestimación de la dimensión metasensible invistió al intelecto de un áurea de valor que, además de otorgarle al ser humano cierta superioridad sobre el resto de los entes, le permitía alcanzar los pretendidos objetivos de progreso y desarrollo. Ello generó un optimismo respecto de la ciencia y la tecnología, que las convirtió en modelo de excelencia, en objetivo último y superior de la humanidad.

Este optimismo científico fomentó, a su vez, una preocupación general por la seguridad y el control, que afectó a todos los ámbitos de la vida individual y social, incluido el nacimiento. La serialización y sistematización de los partos se volvió una necesidad para poder controlarlos, dominarlos, mecanizarlos y volver las prácticas médicas reproducibles en un ámbito de bajo riesgo. Ello acarreó la exigencia de calcular los tiempos del proceso, clasificándolos en patrones estándar de dilatación cervical, fijando plazos, con topes de alerta y topes de intervención. La variación de esos estándares habilita, en consecuencia, la intervención automática e inmediata para adecuar el proceso al criterio científico preestablecido.

Esta estandarización permitió identificar a priori ciertos riesgos de desarrollar complicaciones durante el parto, generando así las oportunidades de administrar drogas como la oxitocina-, de indicar una cesárea o de trasladar a la gestante a una institución que ofrezca un nivel de mayor complejidad con el fin de mitigar cualquier peligro percibido $^{(55)}$. Este proceso de medicalización e intervención del parto tuvo, en un principio, un fuerte impacto positivo en la disminución de los porcentajes de mortalidad perinatal. Ello condujo, sin embargo, a la sobrevaloración de las intervenciones, estandarizándolas como el único modelo "seguro" de parir y nacer, centrado en un asistencialismo médico e institucional unilateral y hegemónico ${ }^{(15)}$.

La sistematización de los nacimientos adoptó una dinámica desencadenante, por la que cada intervención conduce a otra intervención ${ }^{(18,56)}$. Ello se plasma a menudo en los procedimientos de traslado de la gestante a las instituciones de salud. El paso desde un ambiente conocido y seguro -como el del hogar de la gestante, donde habitualmente inicia el trabajo de parto- al ambiente institucional -desconocido y asociado a experiencias de enfermedad- suele activar el sistema simpático de alerta. Ello genera que se detengan las contracciones y, por lo tanto, la necesidad de administrar oxitocina para continuar con el curso de la intervención. La oxitocina sintética produce, a su vez, contracciones más dolorosas. Ello aumenta las exigencias de analgesia y también el intervencionismo. La administración de analgesia, por su parte, se encuentra íntimamente relacionada con el aumento del número de cesáreas, lo cual ha generado una preocupación a nivel mundial, en tanto la cesárea trae aparejada efectos nocivos a corto y a largo plazo, tanto para la gestante como para el recién nacido ${ }^{(19,20,21)}$.

De esta manera, la estandarización de los nacimientos posibilitó un proceso de industrialización, que asimilaría las instituciones de parto a "fábricas" de parir. Este circuito estandarizado del proceso del parto, cual cinta fordista, permitió su incorporación al circuito económico. La monetización de los estándares produjo, a su vez, la reducción de los tiempos del parto a fin de adecuarlos a los tiempos breves del mercado. Ello implicó el aumento de la intervención, instrumentalización y medicalización de los procesos del nacimiento ${ }^{(15)}$.

\section{Hegemonía y hostilidad}

El modelo tecnocrático del parto se asienta sobre una concepción subjetivista centrada en el 
concepto de identidad. Esta concepción pondera la hegemonía del "yo", de la identidad individual, generando una dinámica autorreferencial e individualista que justifica toda imposición identitaria como aseguramiento de la autoposición de ese yo hegemónico. En esta dinámica autorreferencial y centrípeta termina imponiéndose la identidad más fuerte, la que domina y cosifica toda alteridad, convirtiéndola en un objeto más del "entorno".

Bajo esta lógica dominial y jerárquica se construye la relación asimétrica médico-gestante. La toma de conciencia de esta asimetría imprime en la relación una dinámica de confrontación, en la que el sujeto cosificado se siente sometido por un poder que debe rechazar y combatir. El espacio de interacción intersubjetiva se convierte, de esta forma, en campo de batalla, donde el sometido busca empoderarse para defenderse frente al poderoso que lo somete.

En efecto, el discurso del empoderamiento responde a esta lógica identitaria de la subjetividad que configura una forma de convivencia social individualista. Esta funciona según una dinámica de hostilidad cimentada en un esquema liberal que supone una convivencia, en la que las libertades individuales no pueden relacionarse más que a partir de un vínculo beligerante. De esta socialidad de la identidad y la subjetividad resulta la concepción de la convivencia como un agregado de individuos cuya autoafirmación supone necesariamente la exclusión de las otras identidades, de las otras subjetividades, contra las que se compite. Convivencia como interacción hostil de libertades que se autolimitan y se autoexcluyen. Libertades de progreso, que compiten y se excluyen en su perseverar en el ser. Libertades que solo buscan medrar, en una lucha que siempre es excluyente y en la que el otro siempre, necesariamente, es un contrincante.

Esta lógica del empoderamiento, en la que todos son adversarios de todos, subyace tanto al paradigma biomédico como a aquellas reivindicaciones feministas que lo combaten desde un reclamo de "empoderamiento indi-

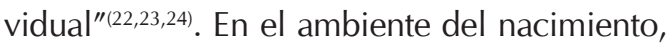
esto se plasma en la actitud de reciprocidad por la que se genera una reacción especular contra aquello que se intenta conjurar. Se trata de la conquista de un centralismo que ninguna de las partes contrapuestas pone en cuestión, sino al que se aspira sin más. El centralismo médico busca ser reemplazado por el centralismo de la gestante, que aspira a recuperar la hegemonía que le pertenece ${ }^{(17)}$.

\section{PARTO, CORPORALIDAD Y GOZO}

Al escindir interioridad de corporalidad y de esta manera objetivar el cuerpo y todo proceso que exceda a la conciencia, el modelo asistencialista del nacimiento neutralizó -menospreciándolos, en tanto meras contingencias- los aspectos fisiológicos, psicológicos, emocionales y ambientales involucrados en el proceso de embarazo y nacimiento. Además, al jerarquizar el conocimiento científico frente a cualquier otro tipo de conocimiento, el modelo hegemónico del cuidado de la salud soslayó una cantidad no menor de saberes prácticos y costumbres respecto de la salud, que las sociedades no occidentalizadas ya tenían incorporadas culturalmente, imponiendo de esta manera un cambio de paradigma en relación con las formas tradicionales locales de nacer ${ }^{(19)}$.

La expansión y consolidación institucional de este paradigma fueron acompañadas no solo por la disminución del número de muertes perinatales, sino también por el aumento de una consideración general negativa respecto del momento del parto, sobre todo desde el punto de vista de las gestantes, que cada vez más identifican el parto como un momento por el que "hay que pasar", privándose así las mujeres -pero también los nacientes, las familias y los profesionales de la salud- de la posibilidad de ser partícipes, de vivir, de experimentar el acontecimiento tan único, tan significativo, tan maravilloso, del nacimiento en cuanto tal ${ }^{(57)}$.

Ante esta incapacidad de vivir en forma gozosa, la experiencia del nacimiento responde a una sedimentación cultural de significado consolidada en la modernidad, que 
influyó de manera particular en los actores que participan del momento del parto. Ahora bien, recuperar esta capacidad de gozo significa recuperar un sentido positivo de lo sensorio-corporal en sí mismo.

\section{La recuperación del cuerpo}

La preponderancia de lo corpóreo-sensorial en el momento del nacimiento encierra un potencial para recuperar la corporalidad alienada por el paradigma tecnocrático. Recuperar el cuerpo en clave ético-relacional significa deconstruir la concepción de subjetividad sostenida por el intelectualismo racionalista que, para poder controlarlo, convirtió al cuerpo en objeto, escindiéndolo así de la subjetividad. Es por esto, precisamente, que no se trata aquí de contraponer una supuesta "naturaleza" a la tecnocracia biomédica. Pues no solo se procura escapar a un discurso metafísico-naturalista, sino que ante todo se trata de abrir la posibilidad a la reactivación de una praxis antes dada por obvia, y luego solapada por el discurso cientificista.

A pesar de todo intento de dominio y control, el parto ocurre como acontecimiento imprevisible por antonomasia, pues en él se activan circuitos corporales psico-neuro-inmuno-endocrinos que actúan de manera inconsciente $^{(19)}$, que generan un "estado alterado de conciencia” ${ }^{\prime 25)}$. Por eso, la perturbación que genera la recuperación de la corporalidad deriva en la incomodidad de tener que lidiar con una situación constitutivamente incontrolable.

Lo indomable del nacimiento proviene de ese aspecto del cuerpo no consciente. Por eso se trata aquí de recuperar una nueva dimensión de sentido de lo corporal, o mejor dicho, de recuperar "el origen corporal del sentido"(26) a partir de su carácter contingente, idiosincrático, que determina su ser "incontrolable", imprevisible. Pues, aunque el idealismo racionalista haya procurado instaurar lo contrario, el sentido emerge precisamente de esa singularidad insustituible de lo acontecimiental; en este caso, de la gestualidad inimitable de los partícipes del nacimiento ${ }^{(26)}$.
La contingencia significante del nacimiento reside, justamente, en la paradoja que implica la simultánea exposición y retracción del cuerpo de la gestante: el cuerpo parturiento, al mismo tiempo que habilita la intervención, al exponerse, se sustrae en su incontrolabilidad y su imprevisibilidad a todo control.

Este sustraerse de la parturienta a toda posibilidad de control se pone en evidencia particularmente en la enajenación total del momento del nacimiento, cuando la conciencia cede todo lugar al cuerpo que, en el paroxismo del parto, se escapa al dominio de la técnica ${ }^{(25)}$. Ahora bien, en este escaparse, en este sustraerse, es donde reside su dignidad. En efecto, la dignidad no refiere a una esencia o a una idea de valor inherente al "concepto" de cuerpo humano, sino que se realiza efectivamente como un sustraerse o retirarse frente a aquello que pretende manipularla. La dignidad coincide, precisamente, con esa distancia, con esa "separación"(27), insuperable e infranqueable, que determina el carácter mismo de alteridad y diferencialidad por el que el otro se pone como un otro, retirándose frente a toda intervención identitaria del poder que lo confronta.

La vulnerabilidad habilita de esta forma, por un lado, la intervención pero, al mismo tiempo, la separación y la distancia -la sustracción al control- interpelando a la responsabilidad. En efecto, en la vulnerabilidad del cuerpo en el momento del nacimiento, se hace presente, a través de su misma "retracción" pudorosa, un imperativo de protección de un valor constitutivo de lo corporal en cuanto tal. La vulnerabilidad realiza, de esta forma, la dignidad, pero con un gesto ambiguo, en cuanto requiere la intervención pero, al mismo tiempo, la limita y orienta.

Así se perfila la noción de responsabilidad, que resulta más primigenia y prioritaria que la noción de "control" y "libertad", puesto que "proteger" no es lo mismo que controlar. La dignidad que proviene de la vulnerabilidad es, de esta forma, la que otorga la fuerza ética y su razón de ser al imperativo de protección que aproxima a los sujetos intervinientes revistiéndolos de su carácter de prójimos ${ }^{(28)}$, conmoviéndolos, 
implicándolos, vinculándolos, antes "de toda toma de conciencia" respecto de sus funciones y posibilidades ${ }^{(29)}$.

En este sentido la vulnerabilidad coincide con una forma de dignidad sin prerrogativas, una dignidad que, paradójicamente, proviene de un "no-poder", de una debilidad, de una fragilidad. Debilidad que, sin embargo, genera una fuerza que ordena, que manda la protección ${ }^{(30)}$. La fuerza de esta dignidad radica precisamente en su debilidad.

Este imperativo que emana de los cuerpos-vulnerables parturientos reconfigura el rol de los cuerpos de los que asisten al parto correlativamente como cuerpos-responsables, a partir de esa débil fuerza de la vulnerabilidad que los compele con su mero comparecer. Responsabilidad que proviene de la corporalidad que determina un tipo peculiar de "cercanía", a saber, la de una proximidad de prójimos ${ }^{(31,32)}$.

Resignificar el cuerpo por su proximidad implica concebirlo como relación, como interdependencia en el plano de un espacio ético ${ }^{(33)}$. Significa reestructurar la subjetividad a partir de su carácter esencialmente relacional. Esta vía ética de acceso a lo corpóreo-carnal subvierte y trastorna la lógica racionalista de la dominación que se sigue a partir del conocimiento y la voluntad, en tanto pone en cuestión todo acceso que reduzca lo corporal a su mero carácter científico-cognoscitivo o político-sociológico, limitando su comprensión a la sola objetividad de su ser cosa o a su carácter de instrumento de realización de la autonomía como despliegue de la libertad.

Por eso, la proximidad ética por la cual se recupera el cuerpo como ocasión de proximidad y responsabilidad no recibe su sentido a partir de la idea de un espacio geométrico de mera contigüidad físico-objetiva, donde prima la simetría y la reciprocidad. Pues la determinación ética que cualifica a los cuerpos de los que asisten a un parto no se sigue de una mera constatación o descubrimiento del cuerpo parturiento que, en tanto objeto corpóreo, físico, "natural", estaría revestido de una especial forma de contingencia por la que escaparía a la capacidad cognoscitiva que lo intenta comprender, controlar. El cuerpo parturiento al que el profesional asiste no se define en su sentido último como una fuerza de carácter ontológico-físico por la cual los cuerpos se enfrentan. Su estar corpóreo no se reduce al mero hecho físico de constituir un vector de fuerza que se contrapone al mismo nivel del cuerpo que lo enfrenta. El cuerpo incontrolable que se sustrae al dominio no lo hace tampoco a partir de la mera fuerza de una voluntad "empoderada" que contrarrestra a otra voluntad más poderosa. Su retracción pudorosa del dominio y el control médico no ocurre como empoderamiento, no habilita ningún espacio político, comprendido como arena de la lucha por el reconocimiento de libertades individuales contrincantes.

En cambio, el espacio de proximidad que establece la corporalidad confirma la asimetría que implica la vulnerabilidad, pues la responsabilidad proviene justamente de ella. Asimetría que, más allá de toda reciprocidad, se presenta urgente e inaplazable.

\section{La recuperación del gozo}

La escisión racionalista, mecanicista y mercantilista del proceso del nacimiento afianzó el significado cultural del acontecimiento del parto como acto o práctica puramente médica profesional. Ello generó una desvinculación entre los partícipes del nacimiento, que se tradujo en un extrañamiento de la gestante no solo respecto de los asistentes al parto, sino también respecto del contexto, del naciente y del propio cuerpo.

Esta desvinculación se plasmó en una creciente neutralización de las dimensiones emocionales, afectivas, sensoriales y relacionales del parto, mientras se priorizaron otras dimensiones como las fisiológicas, técnicas, políticas y económicas. La industrialización y consecuente transformación del parto en mercancía canceló aquellas dimensiones que no revistan valor de intercambio monetario, dimensiones relacionales, constitutivas de los vínculos ecológicos, con lo humano y con lo no humano. 
Sin embargo, las dimensiones relacionales soslayadas reaparecen, están presentes, se muestran en los cuerpos de las gestantes en forma de experiencias negativas de parto $^{(34)}$ : miedos al parto, angustias perinatales, depresiones postparto y en los cuerpos de los nacientes y nacidos en las experiencias de desapego, frustración y abandono, cuyas consecuencias psicológicas e incluso fisiológicas, así como sus efectos epigenéticos y sociales hoy todavía no se llegan a terminar de dimensionar ${ }^{(35,36,37,38)}$. Todas experiencias que la medicina moderna, de la mano de la farmacéutica, no sabe sino camuflar, incorporándolas incluso también a su circuito económico.

Incluso las tendencias más vanguardistas, que procuran una experiencia positiva del parto no alcanzan a considerar el rol de la dimensión ecológico-relacional en el momento del nacimiento ${ }^{(39)}$. El peso del paradigma cientificista consigue todavía sostener el parto en su mera dimensión objetiva como un acontecimiento exclusivamente médico, en el que gestante y naciente comparecen enajenados, cosificados, entregados a las manos del profesional en el marco de un sistema de salud que los acoge con deontológica indiferencia, "como a uno más". De esta forma, la gestante es desvinculada de su corporalidad, así como del potencial relacional que esta encierra no solo con los demás humanos, sino también con todo lo no humano que la rodea.

Es esta separación, esta desvinculación de lo corpóreo la que efectúa la indiferencia respecto de la alteridad, "el otro no me concierne", habilitando así una "toma de distancia emocional" del profesional respecto de la gestante y el naciente ${ }^{(40)}$, posibilitando incluso el ejercicio de la violencia ${ }^{(41)}$.

La recuperación del cuerpo en tanto proximidad posee, sin embargo, el potencial para reactivar la dimensión relacional del nacimiento, rehabilitándolo como una experiencia gozosa, como acontecimiento de encuentro.

La categoría de "gozo", empero, tan cara a la situación de parto, lejos de reducirse a una situación psicofisiológica y psicoafectiva de la parturienta, refiere a una cuestión mucho más profunda. El gozo, tal como lo explicita Levinas ${ }^{(27)}$, constituye la forma de vinculación no-objetivante de la subjetividad respecto del medio en el que se encuentra. A través del gozo se da una forma intencional de relación con las cosas sui generis, por la que estas no se entregan como meros objetos para una conciencia que los representa. Tampoco constituyen los útiles que, dentro de un sistema, forman parte del proyecto de una subjetividad que despliega a través de ellos sus poderes y posibilidades. El mundo, el entorno, no es un conjunto de objetos representados en el gozo, sino aquello de lo que se vive ${ }^{(27)}$, en el sentido de que no puede haber constitución total de aquello que, en último término, es condición de la constitución misma. El gozo testimonia el exceso de sentido propio del entorno, por el cual toda subjetividad se encuentra en su actividad cognoscitiva constituyente como ya constituida por aquello que intenta constituir ${ }^{(42)}$. El medio es ya siempre antes el "punto de apoyo", la base, el lugar a partir del cual se lleva a cabo la constitución. Y la forma primordial de relacionarse con ese entorno, antes que objeto, es en el gozo corporal de una intencionalidad vital irreductible.

Este gozo, sin objetividad, de la afección, de la carnalidad de la conciencia ${ }^{(27)}$ es un gozo sin poder, sin rédito, sin utilidad, sin morigeración. Acontece incluso en medio de la fatiga, la tensión y el dolor como una de sus modulaciones.

En el caso concreto de la parturienta, se trata de un gozo profundo, análogo incluso al orgasmo, vehiculizado y sostenido por la propia oxitocina ${ }^{(43,44)}$, y que realiza toda la humanidad de la gestante en su entero acto de darse. Es precisamente el gozo de darse, el gozo fecundo de la entrega. La entrega total de sí, que convoca casualmente a los mismos órganos y hormonas que el acto sexual ${ }^{(19)}$, en un complejo, inexplicable momento que condensa una de las experiencia más preciadas de la humanidad, momento en el que el yo es otro ${ }^{(45)}$.

El instante del paroxismo del gozo o del dolor en el instante del parto son vida sentida, vivencia radical, no reintegrable en la vida consciente $^{(42)}$ que todo lo explica, simplifica 
y banaliza para estabilizarlo y controlarlo. Por eso, precisamente, el paroxismo afectivo que tiene lugar en el parto no se puede poner en conceptos, para expresarlo atinadamente siempre faltan las palabras.

\section{La recuperación de la diversidad}

La exuberancia de lo senso-corpóreo en el momento del parto, que requiere más bien de oscuridad y calidez, realizándose además de forma impura, es refractaria a la luz, a la frescura y a la pureza de la razón. Esta falta de razón, este estado alterado de concien$\mathrm{cia}^{(35,46)}$ en el que sistema simpático y parasimpático convocan al inconsciente ${ }^{(47)}$, son justamente los que habilitan una recuperación simbólica de lo corpóreo como lenguaje de proximidad.

En tanto cercanía ética con la alteridad, la proximidad ocurre "sin razón", sin previsión, como espontaneidad imprevisible pues, antes de ser una práctica consciente, constituye el imperativo de protección, la fuerza del llamado tímido de la alteridad pudorosa que, vulnerable, convoca a tomar postura, solicita respeto, a la vez que implora protección.

En el parto se muestra de manera paradigmática cómo la proximidad, el acercamiento de la alteridad, ocurre de manera concreta a la vez que como ecología del lenguaje. Pues se trata de una práctica humana significada culturalmente. Ello en tanto el trato del otro está determinado por la forma de dirigirse a él, a través del lenguaje, que plasma a su vez una determinada forma de concebir el cuerpo e incluso de relacionarse con la alteridad del otro.

Resignificar el parto desde la dimensión ética que lo define implica reconsiderar la proximidad propia de lo corpóreo-sensorial, que acerca al otro, tanto sea humano como no humano, cualificándolo como prójimo. Significa pues revalorizar el espacio de la alteridad, lugar utópico de su encuentro, que implica la cuidadosa retirada de la identidad del guardián, que interviene tan solo para proteger, para cuidar, para responder a la prerrogativa de protección del vulnerable. Se trata de un hacer lugar a la alteridad respetando su existencia, su ser otro, su diferencia ${ }^{(48)}$ lo cual se concreta en último término como deferencia frente al más débil.

Esta resignificación de lo corpóreo-sensorial como proximidad, como espacio para lo otro en cuanto tal, para la diversidad, acerca, aproxima a toda alteridad en una amistad sororo-fraterna que redimensiona la esfera de lo público-social como red que vincula con los pares y con los diferentes ${ }^{(41)}$.

Por lo tanto, reconsiderar la primariedad de lo corpóreo-sensorial en el parto implica contener la fuerza expansivo-centrípeta de la identidad, para dar lugar a la alteridad, a la diferencia, a la diversidad. Es el asistente del parto, el profesional, que cede lugar a la gestante que puja, que espera sus tiempos. La madre que da lugar al asistente para que intervenga cuando lo necesita. Los acompañantes que empatizan con la fatiga de la gestante, que hacen lugar a su reclamo, a su voz. Es la gestante que pide agua y la recibe. Es el agua que satisface a la gestante. Es la oxitocina que hace vibrar a la madre, y la madre que vibra a su compás ${ }^{(49)}$. El profesional que hace lugar al acompañante para que se acerque. Es el acompañante que masajea la espalda de la madre y la madre que cede lugar al naciente. Es la luz que se atenúa, que se apaga para dar lugar a la oscuridad que acogerá al naciente. El microbioma de la madre que, cual áurea protectora, pasa al naciente que nace. La madre y los asistentes, que reciben la nueva vida y se retiran, para hacerle un lugar. En el mundo distópico de la ontología, donde cada uno lucha por su lugar bajo el sol(11), se da esta situación peculiar en la que prima el hecho de hacer lugar al otro, generándose de esta forma un espacio ético o utópico en el que la retirada de la identidad hace lugar a la diversidad.

Significa reconsiderar todas las relaciones volviendo a ponderarlas, tanto con los humanos como con lo no humano, a partir de esta experiencia colectiva que nos devuelve al significado cultural del nacimiento como acontecimiento ecológico, plural, socioambiental.

Esta perspectiva ecológica del parto amiga no solo a los partícipes humanos del parto, a la gestante con su propio cuerpo, con 
el naciente, con los asistentes humanos, con los "profesionales de la salud", sino también con cada uno de los microbios que, de manera secreta pero segura, asisten al parto y la lactancia naturales, tornándolos irreemplazables por ningún proceso similar ${ }^{(50,51,52)}$.

Esta perspectiva ecológica recupera también el rol del ambiente, el espacio, la luz, el agua, la tierra y el aire en el proceso del nacimiento, en particular, en relación con su decisiva influencia en la activación del sistema parasimpático en cuanto a la sensación de seguridad y acogimiento ${ }^{(19,53)}$.

La recuperación de la diversidad que postula esta ecología del parto implica también el reconocimiento de la diversidad de formas de parir. Ya que no hay una forma hegemónica de hacerlo estamos llamados a reconsiderar la diversa pluralidad cultural que constituye el hecho de parir ${ }^{(53)}$.

\section{POR UNA CORPORALIDAD DE LA RESPONSABILIDAD}

La propuesta acerca de una aproximación ecológica del parto radica en la recuperación de su sentido relacional. Significa concebir el parto a partir de las relaciones en el que su mismo acontecer se despliega y realiza. Relaciones con la alteridad tanto humana como no-humana, abarcando así tanto lo social como lo ambiental, en tanto que dichas relaciones se redefinen a partir de la dinámica de la responsabilidad.

Se trata, empero, de una responsabilidad que "inviste" a los asistentes al parto más allá de sus compromisos conscientes y sus obligaciones deontológico-profesionales. Pues toda intervención en el hecho mismo significa la intromisión en un ámbito de intimidad ajeno, en el lugar propio del otro. En el parto, se muestra de manera paradigmática esta intromisión en la esfera íntima de la gestante que, pudorosa y expuesta, se retira, aproximando al que la enfrenta, invistiendo y condicionando su libertad de acción (profesional), impidiendo su indiferencia, obligándolo a la deferencia. El cuerpo, en proceso de parto, interpela a la responsabilidad. Una responsabilidad a la que nada ni nadie en el entorno se puede sustraer.

Responsabilidad por la cual el yo está a cargo del otro a su pesar. Pues concierne y afecta al yo desde más acá de su libertad. Impide por eso la indiferencia de una manera originaria, en tanto actúa siempre ya antes de cualquier compromiso, interés o conciencia del deber. Responsabilidad primera, anterior a cualquier deontología médica, que inhabilita cualquier toma de distancia, cualquier no-implicación. Y que por eso ocurre en el ámbito corporal de la proximidad, como cercanía ética, más allá de la contigüidad accidental y contingente de los cuerpos de la geometría que, en la reciprocidad plana de lo neutro, no tienen nada que ver unos con otros.

Esta redefinición relacional, que a la vez resignifica el parto como acontecimiento de proximidad, reestructura la noción misma de subjetividad que, a partir de la responsabilidad, corre su eje desde la identidad a la alteridad, pues la subjetividad que estructura la responsabilidad se encuentra determinada por la alteridad que la define. En este sentido, puede postularse la maternidad como arquetipo de una subjetividad alterada. Esta subjetividad de la responsabilidad se encuentra estructurada maternalmente, en cuanto gesta, a la alteridad en su seno más íntimo ${ }^{(30,45)}$.

\section{Perspectivas}

La responsabilidad que redefine el parto como acontecimiento ecológico-relacional, al deponer la soberanía del yo, inspira un retorno a la interioridad de una conciencia no-intencional/11), retorno que devuelve al yo la mala conciencia frente a su mero existir y a su propio poder-ser, lo cual contrasta, a su vez, con la evidente fragilidad del otro, en su vulnerabilidad y exposición. Esa responsabilidad desactiva el paradigma político de la identidad al cuestionar y revertir la lógica hobbesiana del poder como hostilidad intrínseca a la humanidad; refiere a la alteridad en cuanto tal, en su diferencia que exige deferencia, por lo que restablece la diversidad y la riqueza de la convivencia 
en la diferencia, de manera de recuperar el sentido propiamente social del parto como "acontecimiento" colectivo, ecológico, en el que la "u-topía" se realiza como el efectivo hacer lugar a cada otro para una efectiva convivencia plural. Convivencia que resignifica el paradigma biomédico del nacimiento como evento aséptico meramente bio-fisiológico, que no anula la fatiga, el esfuerzo, e incluso el dolor del desprendimiento, de la separación, del nacimiento. Convivencia como el puro desinterés que resignifica ese esfuerzo, incluso con el placer y el dolor en la conmoción de la acogida del otro, con la posibilidad de lo impredecible, de lo inevitable, de lo incontrolable. Convivencia que no implica dejar todo al azar, sino superar la dualidad del racionalismo moderno mentecuerpo/objeto, que pretende negar, anular el carácter acontecimiental, espontáneo, del nacimiento, de la vida.

Acontecimiento que reactiva el gozo profundo del encuentro con el naciente, pero también con el propio cuerpo, con los demás asistentes al parto -humanos y no humanos-; con la tierra, que es también madre de las madres; con una trascendencia que se hace efectiva en una espiritualidad que no coincide enteramente con el saber ${ }^{(54)}$. Ocasión de experiencias gozosas que reactivan el potencial del parto como un acontecimiento digno de ser vivido.

\section{AGRADECIMIENTOS}

Esta investigación fue Ilevada a cabo en el Instituto de Ecología Humana y Desarrollo Sustentable de la Facultad de Ciencias de la Salud de la Universidad Católica de Santa Fe en el marco del proyecto "Ecología del parto. Aportes para la construcción de un nuevo paradigma del nacimiento" (Resolución de rectorado No. 10.844 del 30 de agosto de 2019), dirigido por Marisa Espinoza y financiado por la Universidad Católica de Santa Fe.

\section{REFERENCIAS BIBLIOGRÁFICAS}

1. Foucault M. L'ordre du discours. Paris: Gallimard; 1970.

2. Quijano Restrepo M. La arqueología y genealogía de Foucault desde los dispositivos de control en el quehacer político. Analecta Política. 2013;4(5):327-347.

3. O'Malley P. Riesgo, neoliberalismo y justicia penal. Buenos Aires: Ad-Hoc; 2006.

4. Menéndez E. La enfermedad y la curación: ¿Qué es medicina tradicional? Alteridades. 1994;4(7):1-13.

5. Davis-floyd R. The technocratic, humanistic, and holistic paradigms of childbirth. International Journal of Gynecology and Obstetrics. 2001;75(Suppl 1):S5-S23.
6. Herrero Y. Miradas ecofeministas para transitar a un mundo justo y sostenible. Revista de Economía Crítica. 2013;(16):278-307.

7. Quinche Ramírez VA, Quinche Ramírez MF. Foucault y el análisis genealógico del Derecho. Estudios Socio-Jurídicos. 2006;8(2):29-43.

8. Fernández Guerrero O. Cuerpo, espacio y libertad en el ecofeminismo. Nómadas - Revista Crítica de Ciencias Sociales y Jurídicas. 2010;27(3):1-15.

9. Latour B. Nous n'avons jamais été modernes: Essai d'anthropologie symétrique. Paris: La Découverte \& Syros; 2010.

10. Herrero Y. Economía feminista y economía ecológica: El diálogo necesario y urgente. Revista de Economía Crítica. 2016;(22):144-161.

11. Levinas E. Entre nosotros: ensayos para pensar en otro. Valencia: Pre-Textos; 2001.

12. Sibrian N. De máquina a proyecto: El cuerpo en el nuevo espíritu del capitalismo. Reflexiones. 2017;95(1):143. doi: 10.15517/RR.V95I1.27659.

13. Merchant $C$. The scientific revolution and the death of nature. Isis. 2006;97(3):513-533.

14. Campiglia M. Erosionar la institución. Nueva Antropología. 2017;30(86):54-77. 
15. Davis-floyd R. Perspectivas antropológicas del parto y el nacimiento humano. Buenos Aires: Fundación Creavida; 2009.

16. World Health Organization. Appropriate technology for birth. The Lancet. 1985;326(8452):436-437.

17. Goberna Tricas J. Autonomía, heteronomía y vulnerabilidad en el proceso de parto. ENE Revista de Enfermería. 2012;6(1):70-77.

18. Aragón M. Violencia obstétrica vs parto respetado: Apuntes para un debate urgente a través del texto de la Ley Nacional. X Jornadas de Sociología. Facultad de Ciencias Sociales, Universidad de Buenos Aires, Buenos Aires; 2013.

19. Rodrigáñez Bustos C. Pariremos con placer. Madrid: Crimentales; 2008.

20. Betrán $\mathrm{AP}$, Temmerman $\mathrm{M}$, Kingdon $\mathrm{C}$, Mohiddin A, Opiyo N, Torloni MR, et al. Interventions to reduce unnecessary caesarean sections in healthy women and babies. The Lancet. 2018;392(10155):1358-1368.

21. Visser GHA, Ayres-de-Campos D, Barnea ER, de Bernis L, Di Renzo GC, Vidarte MFE, et al. FIGO position paper: how to stop the caesarean section epidemic. The Lancet. 2018;392(10155):1286-1287.

22. León M. El empoderamiento en la teoría y práctica del feminismo. En: Poder y empoderamiento de las mujeres. Bogota: TM Editores; 2002. p. 59-83.

23. León M. El empoderamiento de las mujeres: Encuentro del primer y tercer mundos en los estudios de género. Revista de Estudios de Género La Ventana. 2001;2(13):94-106.

24. Venier ME. Por qué "apoderar". Boletín Editorial de El Colegio de México. 1996;67:323-330.

25. Olza I, Leahy-Warren $P$, Benyamini $Y$, Kazmierczak M, Karlsdottir SI, Spyridou A, et al. Women's psychological experiences of physiological childbirth: a meta-synthesis. BMJ Open. 2018;8(10):1-11.

26. Alloa E. Reflexiones del cuerpo: sobre la relación entre cuerpo y lenguaje. Eidos. 2014;21:200221.

27. Levinas E. Totalidad e infinito. Salamanca: Sigueme; 1997.

28. Levinas E. La proximidad del otro. Nombres Revista de Filosofía. 1996;6(8-9):281-289.

29. Levinas E. Humanismo del otro hombre. Madrid: Siglo Veintiuno Editores; 2009.
30. Levinas E. De otro modo que ser o más allá de la esencia. Salamanca: Sígueme; 2003.

31. Levinas E. Paz y proximidad. Laguna: Revista de Filosofía. 2006;(18):143-151.

32. Herrero Y. Miradas ecofeministas para transitar a un mundo justo y sostenible. Revista Economía Crítica. 2013;(16):278-307.

33. Levinas E. Ética como filosofía primera. A parte Rei. 2006;(43):1-21.

34. Giraldo Montoya DI. Experiencias de las mujeres durante el trabajo de parto y parto. Avances en Enfermería. 2016;33(2):271-281.

35. Olza-Fernández I, Marín Gabriel MA, GilSanchez A, Garcia-Segura LM, Arevalo MA. Neuroendocrinology of childbirth and mother-child attachment: The basis of an etiopathogenic model of perinatal neurobiological disorders. Frontiers in Neuroendocrinology. 2014;35(4):459-472.

36. Sandall J, Tribe RM, Avery L, Mola G, Visser GH, Homer CS, et al. Short-term and long-term effects of caesarean section on the health of women and children. The Lancet. 2018;392(10155):1349-1357.

37. Sandall J, Tribe RM, Avery L, Mola G, Visser GH, Homer CS, et al. Short-term and long-term effects of caesarean section on the health of women and children. The Lancet. 2018;392(10155):1349-1357.

38. Bergman NJ. The neuroscience of birth and the case for Zero Separation. Curationis. 2014;37(2):e1-e4.

39. Oladapo $O$, Tunçalp Ö, Bonet $M$, Lawrie $\mathrm{T}$, Portela A, Downe S, et al. WHO model of intrapartum care for a positive childbirth experience: transforming care of women and babies for improved health and wellbeing. BJOG. 2018;125(8):918-922.

40. Castro R. Génesis y práctica del habitus médico autoritario en México. Revista Mexicana de Sociología. 2014;2(1982):167-197.

41. Campiglia M. Erosionar la institución. Nueva Antropología. 2017;30(86):54-77.

42. Levinas E. Descubriendo la existencia con Husserl y Heidegger. Madrid: Editorial Síntesis; 2005.

43. Komisaruk BR, Whipple B. Non-genital orgasms. Sexual and Relationship Therapy. 2012;26(4):1-17.

44. Blanks AM, Thornton S. The role of oxytocin in parturition. BJOG. 2003;110(Suppl. 20):46-51. 
45. Poleshchuk I. Unfolding flesh towards the other: Levinas' perspective of maternity and the feminine. Problemos. 2013;84:138-152.

46. Dixon L, Skinner J, Foureur M. The emotional and hormonal pathways of labour and birth: Integrating mind, body and behaviour. New Zealand College of Midwives. 2013;48(1):15-23.

47. Uvnäs-Moberg K, Handlin L, Petersson M. Selfsoothing behaviors with particular reference to oxytocin release induced by non-noxious sensory stimulation. Frontiers in Psychology. 2014;5:1-16. doi: 10.3389/fpsyg.2014.01529.

48. Fernández Guerrero O. Cuerpo, espacio y libertad en el ecofeminismo. Nómadas - Revista Crítica de Ciencias Sociales y Jurídicas. 2010;27(3):1-15.

49. Uvnäs-moberg K, Petersson M. Social interaction, growth and healing. Diabetes. 2005;51(1):125.

50. Mueller NT, Bakacs E, Combellick J, Grigoryan $Z$, Dominguez-Bello MG. The infant microbiome development: mom matters. Trends in Molecular Medicine. 2015;21(2):109-117.

51. Ferretti P, Pasolli E, Tett A, Asnicar F, Gorfer $\mathrm{V}$, Fedi $\mathrm{S}$, et al. Mother-to-infant microbial trans- mission from different body sites shapes the developing infant gut microbiome. Cell Host \& Microbe. 2018;24(1):133-145.

52. Blaser MJ, Dominguez-Bello MG. The human microbiome before Birth. Cell Host \& Microbe. 2016;20(5):558-560.

53. Sadler M. Una aproximación a la antropología de la reproducción. En: Mackenna A, (ed.). Reproducción Humana e Infertilidad. Santiago: Mediterráneo; 2012. p. 19-25.

54. Levinas E. El diálogo. Nombres - Revista de Filosofía. 1994;4(5):7-22.

55. Souza JP, Oladapo OT, Fawole B, Mugerwa $K$, Reis R, Barbosa-Junior F, et al. Cervical dilatation over time is a poor predictor of severe adverse birth outcomes: a diagnostic accuracy study. BJOG. 2018;125(8):991-1000.

56. Buckley SJ. Hormonal physiology of childbearing: evidence and implications for women, babies, and maternity care. Washington DC: Childbirth Connection; 2015.

57. Campiglia M. Violentar el nacimiento. El Cotidiano. 2015;(191):79-86.

\section{FORMA DE CITAR}

Viola FI, Bonet de Viola AM, Espinoza M. El racionalismo y la descorporalización moderna del parto: por una ecología del nacimiento. Salud Colectiva. 2020;16:e2548. doi: 10.18294/sc.2020.2548.

Recibido: 11-09-2019 | Versión final: 17-12-2019 | Aprobado: 03-01-2020 | Publicado en línea: 05-03-2020 